\title{
Detailed Characterization of Light Cycle Oil for BTX Production Purposes
}

\author{
Georgina C. Laredo*, Patricia Pérez-Romo, Ricardo Águeda-Rangel, José Escobar and Pedro \\ Vega-Merino. \\ Instituto Mexicano del Petróleo, Lázaro Cárdenas, México
}

*Corresponding Author: Georgina C. Laredo, Instituto Mexicano del Petróleo, Lázaro Cárdenas, México

\begin{abstract}
Samples of Mexican light cycle oils were characterized by several techniques. Physical and chemical characteristics are presented. Besides the usual American Standard Test Methods (ASTM) a gas chromatography - mass spectrometry (GC-MS) technique was presented. Based on the GC-MS technique a detailed chemical characterization method was proposed by considering the retention times and sorting out the compounds as hydrocarbon-type derivatives such as benzene, naphthalene, phenanthrene and alkanes derivatives. This procedure is a useful tool for assessing the feasibility and potential of LCO samples as feedstocks for petrochemical or gasoline production. A sample was also distilled in fractions and characterized for the ASTM and GC-MS methods to define the optimum final boiling point for attaining a certain upgrading method.
\end{abstract}

Keywords: Light cycle oil; BTX, gasoline, chemical characterization, chromatography, mass spectrometry

\section{INTRODUCTION}

Light cycle oil (LCO) is a middle distillate from FCC (fluid catalytic cracking) units with high sulfur (up to 4 wt.\%), nitrogen (up to $400 \mathrm{mg} / \mathrm{kg}$ ), and aromatic contents (up to nearly $90 \mathrm{wt} . \%$ ) [1, 2], which make the processing of this middle distillate very difficult and suitable to comply with the environmental legislation $[3,4]$.

There have been several technological alternatives for producing diesel from LCO and SRGO/LCO mixtures that includes:

- LCO fractionation into light fractions (final boiling point lower than $340{ }^{\circ} \mathrm{C}$ ) to avoid the strong inhibition of aromatics due to competing hydrogenation of those species with that of highly refractory organo-sulfur compounds $[5,6]$.

- Utilization of more active catalysts [7-10]

- Newer and revamped technologies [11-13]

A remarkably interesting alternative for LCO upgrading is obtaining a benzene, toluene, and xylenes (BTX) enriched fraction after hydrogenation/hydrotreating (HYD/HDT) and hydrocracking (HCK) from LCO feedstock. Reaction pathways from LCO (naphthalene as model compound representing diaromatics present in that middle distillate) to a BTX enriched fraction is shown in Figure 1 [14]. After HYD/HDT, the naphthalene derivatives produced 1,2,3,4-tetrahydronaphthalenes (tetralins). In the case of real feedstocks, HDT is required to decrease the amount of sulfur- and nitrogen-bearing contaminants that could act as poison for further processes. Then, the tetralin derivatives were subjected to HCK for BTX production. 


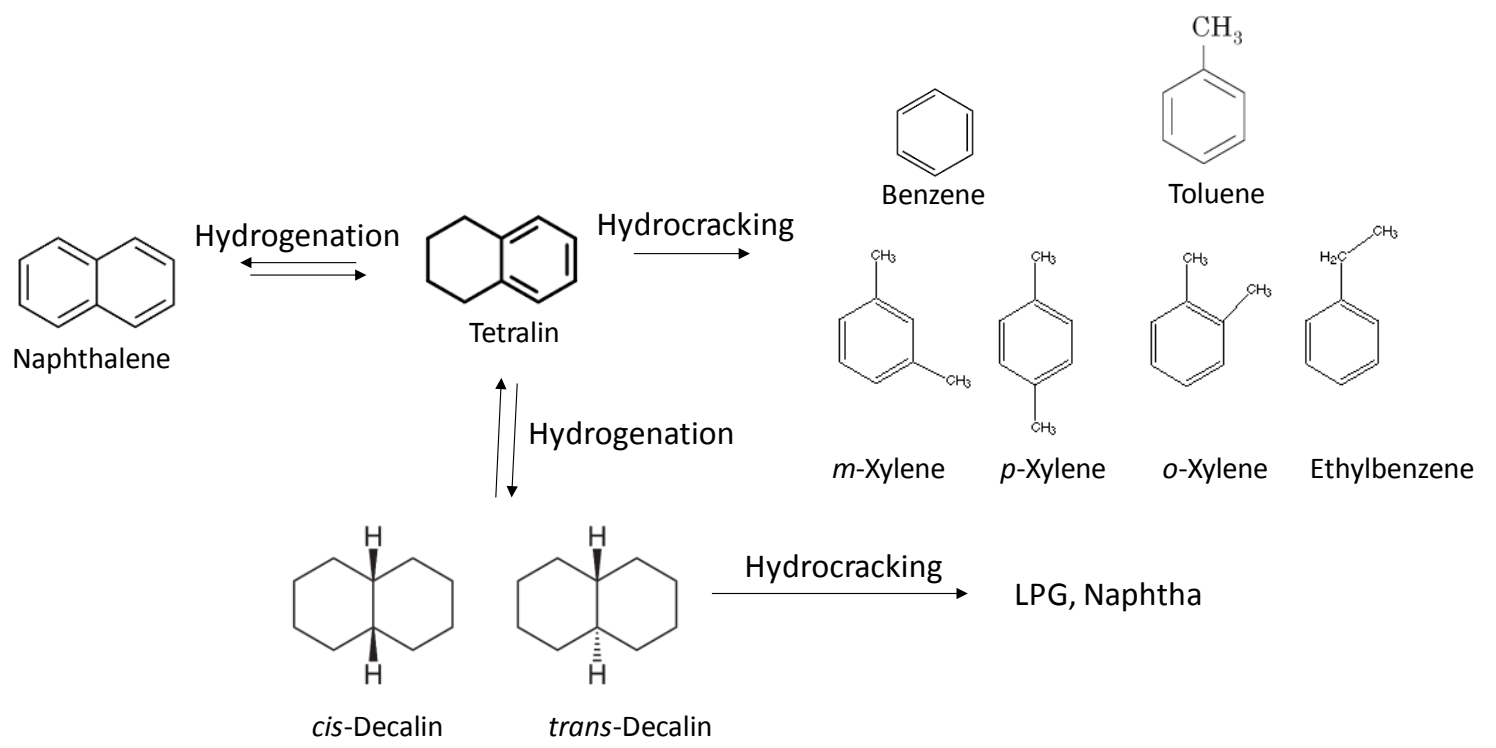

Figure1. Reaction scheme for obtaining BTX and LPG (liquefied petroleum gas) and naphtha from LCO [15]

Physical and chemical characterization of the feedstocks and corresponding products of different processes is crucial to face future refining challenges. Characterization by ASTM D-5186 method [15] provides approximated values of mono-, di- and tri-aromatic compounds in the LCO. However, it was designed for middle distillates with less than $50 \mathrm{wt} . \%$ of aromatic content and it does not describe the chemical structures involved (i.e., benzene or tetralin derivatives in the case of mono-aromatics) or the type of naphthalene derivatives which are present or remain after HYD/HDT and HCK processes. This type of characterization is crucial because each type of species could provide different product slates.

Regarding the corresponding state of the art, detailed chromatograms of fractionated LCO were presented by Choi et al. [16] although no detailed characterization of the crucial compounds was attempted. LCO characterization by using two-dimensional high-resolution gas chromatography and time-of-flight mass spectrometry (TD-GC-HRMS) followed by enhanced software processing has been presented by Bisht and Petri [13] and Alonso et al. [17]. Vendeuvre et al. [18] revealed that by using a comprehensive two-dimensional gas chromatography (GC x GC) combined with the boiling range distribution of complex mixtures allowed them to obtain the group type separation of a gas oil. RuizGuerrero et al [19] studied straight run gas oils (SRGOs), and LCOs and demonstrated the effectiveness of two-dimensional gas chromatography coupled to sulfur chemiluminescence detection (SCD) as a powerful tool for improving characterization and identification of sulfur compounds. Adam et al [20] reported the use of supercritical fluid chromatography (SFC) coupled to a twin comprehensive twodimensional gas chromatography allowed the detailed characterization of middle distillates avoiding the risk of misidentifications. The extended PIONA analysis of middle distillates in one single injection was for the first time reported. Jennerwein et al [21] established a two-dimensional GC x GC-time-offlight mass spectrometric (TOFMS) method the complete group-type quantification of petroleum middle distillates. The combination of these two techniques offered the possibility to distinguish between compounds groups based on their fragmentation patterns where exact retention time information is missing. This method needed the application of Visual Basic Scripting as an analytical tool for the analysis of mass spectral data. Alvarez-Majmutov et al. [22]. reported a technology based on trends followed by the different hydrocarbon families against their boiling point, allowing the chemical characterization of middle distillates. Although the technology is not always reliable due to the presence of different hydrocarbons families of the LCO that does not always follow the predicted normal configuration provided by that authors. The LCO is not a natural occurring mixture and its composition depends highly in the FCC procedure i.e. crudes oils source, HDT or not HDT involvement before FCC, FCC catalyst and configuration. Additionally, the hydrocarbon differentiation is not as carefully as required for the purposes described in this paper.

The main purpose of this work is to provide an accessible method using a GC-MS technique to characterize different LCOs to assess the suitability of each one either for production of valuable petrochemicals or gasoline. 


\section{EXPERIMENTAL}

\subsection{Materials}

LCO samples were kindly provided by PEMEX. The samples were named LCO 1 to 8 .

Distillated fractions: The LCO sample No. 6 was fractionated into nine $20{ }^{\circ} \mathrm{C}$-cuts by using an OlderShaw distillation equipment following the ASTM D86 [15].

\subsection{ASTM Characterization of LCO Samples and Distillation Fractions}

LCO samples were chemically characterized using the ASTM standards shown in Table 1 [15].

Table1. ASTM and UOP characterization methods used for middle distillates and their hydrotreated products [26]

\begin{tabular}{|c|c|c|c|}
\hline Characteristic & \multicolumn{2}{|c|}{ Method } & Description \\
\hline Sulfur, wt $\%$ & ASTM & D4294 & $\begin{array}{c}\text { Standard Test Method for Sulfur in Petroleum and Petroleum } \\
\text { Products by Energy Dispersive X-ray Fluorescence } \\
\text { Spectrometry }\end{array}$ \\
\hline Nitrogen, mg/kg & ASTM & D4629 & $\begin{array}{l}\text { Standard Test Method for Nitrogen in Petroleum and } \\
\text { Petroleum Products by Boat-Inlet Chemiluminescence } \\
\text { Standard Test Method for Trace Nitrogen in Liquid } \\
\text { Petroleum Hydrocarbons by Syringe/Inlet Oxidative } \\
\text { Combustion and Chemiluminescence Detection }\end{array}$ \\
\hline Basic nitrogen, $\mathrm{mg} / \mathrm{kg}$ & UOP & 269 & Nitrogen Bases in Hydrocarbons by Potentiometric Titration \\
\hline Bromine number, $\mathrm{gBr} / 100 \mathrm{~g}$ & ASTM & D1159 & $\begin{array}{c}\text { Standard Test Method for Bromine Numbers of Petroleum } \\
\text { Distillates and Commercial Aliphatic Olefins by } \\
\text { Electrometric Titration }\end{array}$ \\
\hline Refraction index & ASTM & D1218 & $\begin{array}{c}\text { Standard Test Method for Refractive Index and Refractive } \\
\text { Dispersion of Hydrocarbon Liquids }\end{array}$ \\
\hline Chemical composition & ASTM & D5186 & $\begin{array}{c}\text { Standard Test Method for Determination of the Aromatic } \\
\text { Content and Polynuclear Aromatic Content of Diesel Fuels } \\
\text { By Supercritical Fluid Chromatography }\end{array}$ \\
\hline Cetane index & ASTM & D 976 & $\begin{array}{c}\text { Standard Test Method for Calculated Cetane Index of } \\
\text { Distillate Fuels }\end{array}$ \\
\hline Specifity gravity & ASTM & D1298 & $\begin{array}{l}\text { Standard Test Method for Density, Relative Density, or API } \\
\text { Gravity of Crude Petroleum and Liquid Petroleum Products } \\
\text { by Hydrometer Method }\end{array}$ \\
\hline API gravity & ASTM & D287 & $\begin{array}{c}\text { Standard Test Method for API Gravity of Crude Petroleum } \\
\text { and Petroleum Products (Hydrometer Method) }\end{array}$ \\
\hline Atmospheric distillation, ${ }^{\circ} \mathrm{C}$ & ASTM & D86 & $\begin{array}{c}\text { Standard Test Method for Distillation of Petroleum Products } \\
\text { and Liquid Fuels at Atmospheric Pressure }\end{array}$ \\
\hline
\end{tabular}

\subsection{Gas Chromatograph Coupled to Mass Spectrometry Detector (GC-MS)}

LCO samples and distillated fractions were characterized with an Agilent Technologies 6890N gas chromatograph coupled to a $5973 \mathrm{~N}$ mass spectrophotometer (GC-MS) was used by following the EPA method 8270D [23] through SIM mode (quantitative analysis) for naphthalene and phenanthrene derivatives and SCAN mode (qualitative analysis) for the alkanes and iso-alkanes, 1,2,3,4tetrahydronaphthalene (tetralin, T) and decahydronaphthalene (decalin, D). Table 2 shows the retention times of the several compounds found: benzene, naphthalene, phenanthrene, alkenes and $(1,2,3,4-$ tetrahydronaphthalenes/Tetralins) derivatives respectively.

Table2. Retention times $\left(t_{R}\right)$ obtained by the GC-MS method

\begin{tabular}{|c|c|c|c|}
\hline Compound & $\begin{array}{c}t_{R} \\
(\mathrm{~min})\end{array}$ & Compound & $\begin{array}{c}\mathrm{t}_{\mathrm{R}} \\
(\mathrm{min})\end{array}$ \\
\hline Benzene derivatives [24] & & Naphthalene derivatives & 100.9 \\
\hline Benzene & 48.5 & Naphthalene & 100.9 \\
\hline Toluene & 66.9 & 1-Methy-lnaphthalene & 113.5 \\
\hline Ethylbenzene & 80.2 & 2-Methyl-naphthalene & 119.0 \\
\hline$p$-Xylene & 80.4 & 2,6/2,7-Dimethyl-naphthalene & 130.8 \\
\hline$m$-Xylene & 81.5 & 1,3/1,7-Dimethyl-naphthalene & 132.7 \\
\hline
\end{tabular}


Detailed Characterization of Light Cycle Oil for BTX Production Purposes

\begin{tabular}{|c|c|c|c|}
\hline$o$-Xylene & 83.9 & 1,6-Dimethyl-naphthalene & 133.3 \\
\hline 1,3-Dimethyl-benzene & 86.7 & 1,4/2,3-Dimethyl-naphthalene & 135.3 \\
\hline Mesitylene & 92.5 & 1,5-Dimethyl-naphthalene & 135.6 \\
\hline 1-Ethyl-2-methyl-benzene & 93.1 & 1,2-Dimethyl-naphthalene & 137.0 \\
\hline 1,2,3-Trimethyl-benzene & 95.6 & 1,3,7-Trimethyl-naphthalene & 145.1 \\
\hline 1-Methyl-3-propy-lbenzene & 97.0 & 1,3,6-Trimethyl-naphthalene & 146.0 \\
\hline 2-Ethyl-1,4-dimethyl-benzene & 97.4 & 1,3,5/1,4,6-Trimethyl-naphthalene & 147.6 \\
\hline 1-Methyl-2-propyl-benzene & 97.9 & 2,3,6-Trimethyl-naphthalene & 148.2 \\
\hline 1-Ethyl-2,4-dimethyl-benzene & 98.4 & $\begin{array}{c}1,2,7 / 1,6,7 / 1,2,6 \text {-Trimethyl- } \\
\text { naphthalene }\end{array}$ & 149.6 \\
\hline 2-Ethyl-1,4-dimethyl-benzene & 98.8 & 1,2,4-Trimethyl-naphthalene & 151.5 \\
\hline 1,2,3,4-Tetramethyl-benzene & 99.9 & 1,2,5-Trimethyl-naphthalene & 152.5 \\
\hline 1,2,4,5-Tetramethyl-benzene & 100.5 & 1,3,5,7-Tetramethyl-naphthalene & 161.2 \\
\hline 1-Methyl-4-butyl-benzene & 102.2 & 1,3,6,7-Tetramethyl-naphthalene & 162.9 \\
\hline 1-Ethyl-2,4-dimethyl-benzene & 102.3 & $\begin{array}{c}1,2,4,6 / 1,2,4,7 / 1,4,6,7-\text { Tetramethyl- } \\
\text { naphthalene }\end{array}$ & 163.4 \\
\hline (1-Methyl-2-cyclopropen-1-yl)-benzene & 102.5 & 1,2,5,7-Tetramethyl-naphthalene & 164.3 \\
\hline 1-Methyl-4-(1-methylpropyl)-benzene & 102.8 & 2,3,6,7-Tetramethyl-naphthalene & 165.2 \\
\hline 1-Methyl-4-(2-methylpropyl)-benzene & 103.3 & 1,2,3,7-Tetramethyl-naphthalene & 165.7 \\
\hline Pentamethyl-benzene & 104.4 & 1,2,3,6-Tetramethyl-naphthalene & 166.4 \\
\hline (1,3-Dimethylbutyl)-benzene & 104.9 & $\begin{array}{c}\text { 1,2,5,6/1,2,3,5-Tetramethyl- } \\
\text { naphthalene }\end{array}$ & 168.0 \\
\hline 2,4-Dimethyl-1-(1-methylpropyl)-benzene & 105.7 & Phenanthrene & 174.1 \\
\hline 1,4-Dimethyl-2-(2-methylpropyl)-benzene & 106.5 & 1-Methyl-phenantrene & 185.1 \\
\hline \multirow[t]{2}{*}{ 1,3,5-Trimethyl propyl-benzene } & 107.1 & 2-Methyl-phenantrene & 185.7 \\
\hline & & 3-Methyl-phenantrene & 188.0 \\
\hline
\end{tabular}

\section{RESULTS AND DISCUSSION}

\subsection{LCO Characterization by the ASTM Standards [15]}

Sulfur concentration of LCO samples varied from 2.07 to $3.34 \mathrm{wt}$ \% (Table 3). Due to high content of heterocyclic sulfur compounds LCO HDT requires moderate temperature and high hydrogen partial pressures because sulfur removal reaction pathways via hydrogenated intermediaries are inhibited at high temperature and low pressure due to low equilibrium concentrations of the latter species [9]. Distribution of various organo-sulfur compounds in LCO depends on the origin of the processed crude blend, the catalyst type, feed quality and operating conditions used in the FCC units where that middle distillates come from. Benzothiophenes with alkyl substituents containing 1-7 carbon atoms are concentrated in fractions having boiling points below $300{ }^{\circ} \mathrm{C}$ whereas dibenzothiophenes with alkyl substituents containing 1-5 carbon atoms belongs to fractions with boiling points above $300{ }^{\circ} \mathrm{C}$. The three-ring sulfur compounds are one order of magnitude less reactive than the two-ring sulfur species [9].

The total and basic nitrogen concentrations were from 132 to $545 \mathrm{mg} / \mathrm{kg}$ and from 27 to $71 \mathrm{mg} / \mathrm{kg}$, respectively (Table 3). Based on average values, the basic nitrogen represented $15.8 \%$ of the total nitrogen. Nitrogen-rich feedstocks are harmful for the LCO hydrocracking because they have to be processed at higher hydrogen partial pressure and/or lower LHSV in the HDT reactors in order to efficiently reduce the nitrogen content of the effluent to levels acceptable for hydrocracking. Besides, ammonia poisons the acid sites of HCK catalysts resulting in weakened catalyst cracking function and, consequently, in loss of the catalytic activity [10].

Table3. Chemical characterization of LCO samples 1 to 8 by ASTM D5186 method

\begin{tabular}{|c|c|c|c|c|c|c|c|c|c|}
\hline LCO simple & 1 & 2 & 3 & 4 & 5 & 6 & 7 & 8 & Averaged \\
\hline Sulfur, wt\% & 3.22 & 2.4 & 3.34 & 2.68 & 3.3 & 2.94 & 2.28 & 2.07 & 2.78 \\
\hline Nitrogen, mg/kg & 337 & 269 & 544.8 & 253.6 & 346 & 132 & 224 & 319 & 303.2 \\
\hline $\begin{array}{c}\text { Basic nitrogen, } \\
\mathrm{mg} / \mathrm{kg}\end{array}$ & 71.3 & 40 & 57.3 & 48.2 & 38.1 & 54.3 & 45 & 27.3 & 47.7 \\
\hline
\end{tabular}




\begin{tabular}{|c|c|c|c|c|c|c|c|c|c|}
\hline $\begin{array}{c}\text { Bromine number, } \\
\text { g Br } / 100 \mathrm{~g}\end{array}$ & 10.24 & 18.97 & 19.4 & 13.15 & 14.39 & 11.6 & 15.48 & 28.04 & 16.41 \\
\hline $\begin{array}{c}\text { Chemical } \\
\text { Composition }\end{array}$ & & & & & & & & & \\
\hline Mono-Aromatics & 9.40 & 23.60 & 12.70 & 19.80 & 14.70 & 29.30 & 22.00 & 11.10 & 17.83 \\
\hline Di-Aromatics & 70.70 & 51.40 & 56.30 & 52.50 & 54.60 & 44.10 & 45.10 & 55.00 & 53.71 \\
\hline Tri-Aromatics & 7.10 & 8.60 & 14.40 & 6.10 & 6.70 & 2.00 & 5.40 & 5.60 & 6.99 \\
\hline Total Aromatics & 87.20 & 83.60 & 83.40 & 78.40 & 76.00 & 75.40 & 72.50 & 71.70 & 78.53 \\
\hline Aliphatics & 12.80 & 16.40 & 16.60 & 21.60 & 24.00 & 24.60 & 27.50 & 28.30 & 21.48 \\
\hline Cetane Index & 17.9 & 20.7 & 21.08 & 23.62 & 24.8 & 23.7 & 28.7 & 28.3 & 23.60 \\
\hline Specific gravity & 0.91 & 0.97 & 0.98 & 0.94 & 0.96 & 0.9 & 0.92 & 0.965 & 0.94 \\
\hline API gravity & 23.99 & 14.38 & 12.89 & 19.03 & 15.90 & 25.72 & 22.30 & 15.13 & 18.67 \\
\hline $\begin{array}{c}\text { Atmospheric } \\
\text { distillation, }{ }^{\circ} \mathrm{C}\end{array}$ & & & & & & & & \\
\hline IBP & 236.9 & 173.5 & 225.2 & 214.8 & 200.3 & 173.4 & 151.5 & 178.8 & 194.3 \\
\hline 5 vol.\% & 248.2 & 210.7 & 242.6 & 230.7 & 239.7 & 199.6 & 214.5 & 240.7 & 228.3 \\
\hline 10 vol.\% & 250.5 & 221.1 & 246.5 & 236.2 & 249.7 & 207.2 & 221.9 & 257.5 & 236.3 \\
\hline 30 vol.\% & 257.3 & 235.7 & 261.7 & 251.6 & 265.2 & 228.3 & 252.5 & 265 & 252.2 \\
\hline 50 vol.\% & 264.2 & 259.2 & 279.1 & 264.5 & 275 & 248.5 & 268.2 & 277.8 & 267.1 \\
\hline 70 vol.\% & 274.6 & 277.3 & 302.9 & 275.1 & 288.1 & 266.8 & 284.8 & 298.8 & 283.6 \\
\hline 90 vol.\% & 285.5 & 316.3 & 349 & 288.3 & 310.7 & 288.9 & 310.5 & 329.5 & 309.8 \\
\hline 95 vol.\% & 310.2 & 330.6 & 365.8 & 314.3 & 323.9 & 299.9 & 321.6 & 337.3 & 325.5 \\
\hline FBP & 326.9 & 344.2 & 392.3 & 335.6 & 345.8 & 315.5 & 334.5 & 350.5 & 343.2 \\
\hline
\end{tabular}

Aromatics concentrations in LCO samples were in the following intervals (Table 3): mono-aromatics: 9.4-29.3 wt.\%; di-aromatics: 44.1-70.7 wt.\%; tri-aromatics: 2.0-14.4 wt.\%; total aromatics: 71.7-87.2 wt.\%, respectively. According to the average values, the ratio of mono-/di-/tri- aromatics (i.e. 2.6/7.7/1.0), showed a predominant presence of di-aromatics (i.e., $68.4 \%$ of the total aromatics content), which were followed by the mono-aromatic compounds (i.e. $22.7 \%$ of the total aromatics content). Due to the greater stabilization by resonance of mono-aromatic species those compounds are generally an order of magnitude less reactive than di-aromatics [9]. HYD of aromatics is sequential and cracking of the saturated outer ring of tri-aromatics occurs above $427^{\circ} \mathrm{C}$ [9]. HCK of aromatic feeds needs catalysts with good saturation function and moderate-to-high acidity because those species could be cracked only after HYD and show tendency to deposit coke on the catalyst surface [24]. HYD of aromatics are exothermic and reversible reactions with lower equilibrium conversions under practical processing conditions of industrial interest. Thus, increasing temperature to achieve higher saturation reaction rates often results in lower equilibrium conversions, especially at lower pressures. In this line, during LCO $\mathrm{HDT}$ at high hydrogen partial pressure $(7.8 \mathrm{MPa})$ in batch reactor over a $\mathrm{CoMo} / \mathrm{Al}_{2} \mathrm{O}_{3}$ sulfided catalyst [25] the minimum concentration of di-aromatics was found when operating at $360{ }^{\circ} \mathrm{C}$. At higher temperatures $\left(400{ }^{\circ} \mathrm{C}\right)$ thermodynamically favored dehydrogenation reactions resulted in monoaromatics transformation back to corresponding di-aromatics which they came from. Summing up, operating at high hydrogen partial pressure, moderate temperature, low LHSV and using active dualfunction catalysts is recommended to hydrogenate aromatics to an appreciable extent.

High concentration of mono- and di-aromatics could be valuable for BTX production [26]. Following that criterion, in Figure 2 various LCO samples are shown ordered from the most valuable to the least one. Tri-aromatics and alkanes are considered as not suitable for that particular purpose. After processing, poly-aromatics provided an array of hydrogenated hydrocarbons not particularly suitable to produce BTX as shown in reaction pathways of Figure 1. For example, phenanthrene hydrogenation demands for higher temperature and pressure, and enhanced hydrogen consumption as well, producing among other compounds: octahydrophenanthrene (OHP), octahydroanthracene (OHA), tetrahydrophenanthrene (THP) and dihydrophenanthrene (DHP) at 9.07\%, 34.84\%, 18.36\% and 32.85\% [27]. During the hydrocracking procedure, aliphatic compounds are converted to LPG gases [24]. Alternatively, a low presence of all kinds of aromatics and a high presence of long chain alkanes and iso-alkanes can be very suitable for diesel fuel production, as it is known that long linear hydrocarbons increased the quality of the diesel produced [28]. 


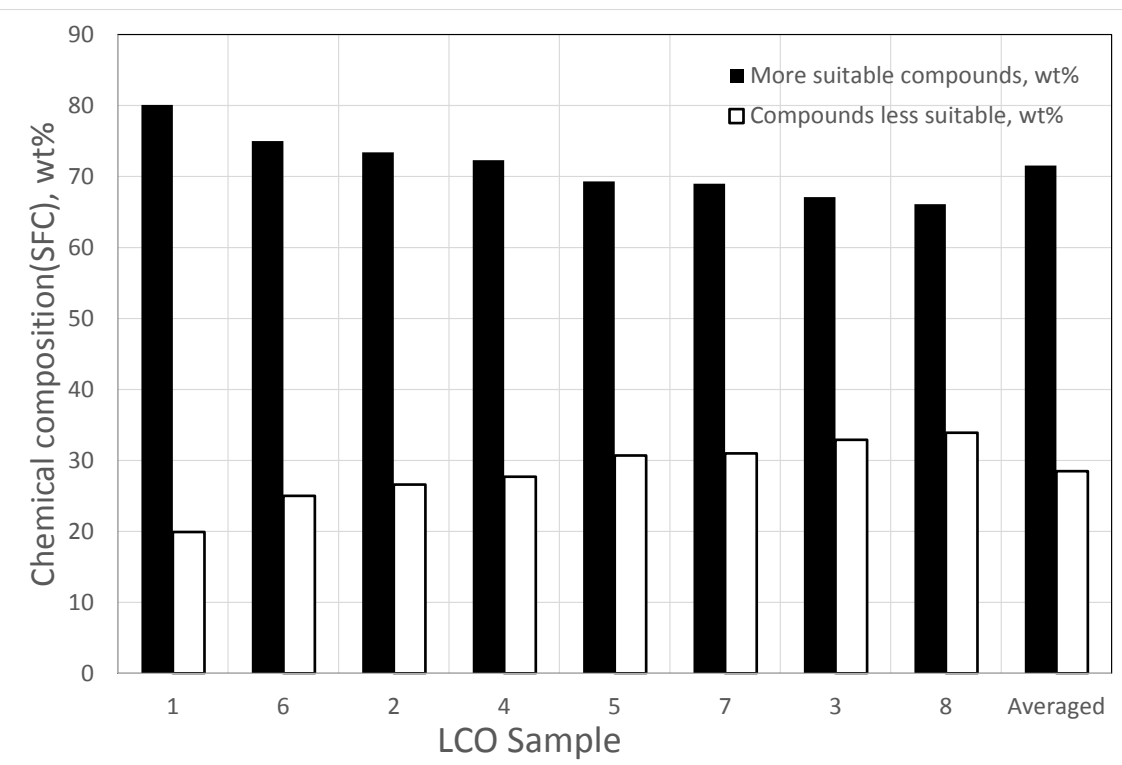

Figure2. Chemical composition of various LCO samples by the ASTM D5183 method, from the most to the least suitable hydrocarbon type distribution for BTX production

Cetane index varied from 17.9 to 28.7 (Table 3), accordingly to the aromatics content. That is, the lowest value of the cetane index (i.e. 17.9) corresponded to the sample of the highest content of both di-aromatics (i.e., 70.7 wt.\%) and total aromatics (i.e., 87.2 wt.\%).

API gravities varied from 12.9 to $25.7^{\circ} \mathrm{API}$. Boiling point ranged from IBP: $151.5-236.9^{\circ} \mathrm{C}$, to FBP: 315.5-392. $3^{\circ} \mathrm{C}$. Higher FBP means higher amounts of heavy aromatics not suitable for BTX production [26].

\subsection{Identification of the LCO Composition by Lumps Using the GC-MS Technique.}

Using mass spectrometry, the samples were analyzed. The retention times $\left(T_{R}\right)$ obtained compared successfully with the values presented by Alonso et. al. [17]. The identified compounds from Table 2 were grouped into lumps according to their chemical type as: alkanes and iso-alkanes, benzene and tetralin derivatives, naphthalene, mono-, di-, tri- and tetra-methylnaphthalenes (MN, DMN, TMN, TMN and TTMN respectively) and phenanthrene derivatives. This type of chemical characterization based on GC-MS chromatography technique of the sample 6 is shown in Figure 3. This characterization represents a fingerprint of a middle distillate and goes beyond the usual characterization of mono-, diand tri-aromatics by the ASTM D5186 method (supercritical fluid chromatography with flame ionization detection, SFC-FID) and it could provide information on the potential of a sample to be used as feedstock in a given process.

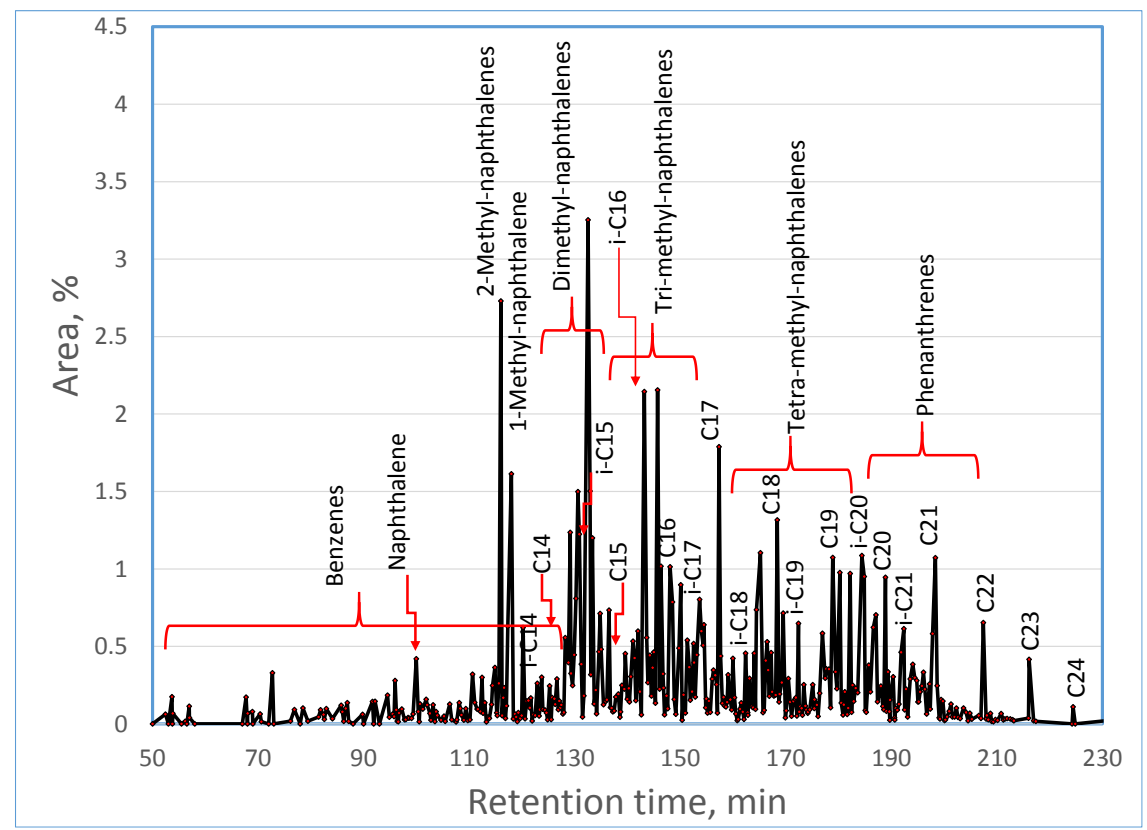

Figure3. Detailed GC-MS analysis of the LCO sample 6 
Table2. Retention times $\left(t_{R}\right)$ obtained by the GC-MS method (continuation)

\begin{tabular}{|c|c|c|}
\hline Compound & & $t_{R}(\min )$ \\
\hline \multicolumn{3}{|l|}{ Alkanes } \\
\hline Tetradecane & & 126.0 \\
\hline Pentadecane & & 137.7 \\
\hline Hexadecane & & 148.9 \\
\hline Heptadecane & & 159.2 \\
\hline Octadecane & & 169.1 \\
\hline Nonadecane & & 178.6 \\
\hline Eicosane & & 187.6 \\
\hline \multicolumn{3}{|c|}{ 1,2,3,4-Tetrahydronaphthalenes /Tetralins) derivatives (only the HDT sample) } \\
\hline Naphthalene, 1,2,3,4-tetrahydro & Tetralin & 97.2 \\
\hline Naphthalene, 1,2,3,4-tetrahydro-2-methyl- & 2-Methyl-tetralin & 104.9 \\
\hline Naphthalene, 1,2,3,4-tetrahydro-1-methyl- & 1-Methyl-tetralin & 106.0 \\
\hline Naphthalene, 1,2,3,4-tetrahydro-5-methyl- & 5-Methyl-tetralin & 111.7 \\
\hline Naphthalene, 1,2,3,4-tetrahydro-1,4-dimethyl- & 1,4-Dimethyl-tetralin & 113.0 \\
\hline Naphthalene, 1,2,3,4-tetrahydro-6-methyl- & 6-Methyl-tetralin & 115.1 \\
\hline Naphthalene, 1,2,3,4-tetrahydro-1,8-dimethyl- & 1,8-Dimethyl-tetralin & 119.6 \\
\hline Naphthalene, 2-ethyl-1,2,3,4-tetrahydro- & 2-Ethyl-tetralin & 120.2 \\
\hline Naphthalene, 1,2,3,4-tetrahydro-2,6-dimethyl- & 2,6-Dimethyl-tetralin & 121.3 \\
\hline Naphthalene, 1,2,3,4-tetrahydro-2,7-dimethyl- & 2,7-Dimethyl-tetralin & 121.9 \\
\hline Naphthalene, 1,2,3,4-tetrahydro-1,5-dimethyl- & 1,5-Dimethyl-tetraline & 123.0 \\
\hline Naphthalene, 5-ethyl-1,2,3,4-tetrahydro- & 5-Ethyl-tetralin & 123.6 \\
\hline Naphthalene, 1,2,3,4-tetrahydro-1,1,6-trimethyl- & 1,1,6-Trimethyl-tetralin & 124.6 \\
\hline Naphthalene, 1,2,3,4-tetrahydro-1,4,6-trimethyl- & 1,4,6-Trimethyl-tetralin & 125.2 \\
\hline Naphthalene, 1,2,3,4-tetrahydro-5,7-dimethyl- & 5,7-Dimethyl-tetralin & 127.8 \\
\hline Naphthalene, 1,2,3,4-tetrahydro-5,6-dimethyl- & 5,6-Dimethyl-tetralin & 128.3 \\
\hline Naphthalene, 1,2,3,4-tetrahydro-1,5,7-trimethyl- & 1,5,7-Trimethyl-tetralin & 129.4 \\
\hline Naphthalene, 1,2,3,4-tetrahydro- 2,5,8-trimethyl- & 2,5,8-Trimethyl-tetralin & 133.5 \\
\hline
\end{tabular}

A comparison between LCO samples 1 and 7 in Figure 4, shows some differences between LCOs. SIM in the GC-MS technique demonstrated the presence of naphthalene derivatives. However, when using the SCAN mode, tetralin derivatives could be observed.

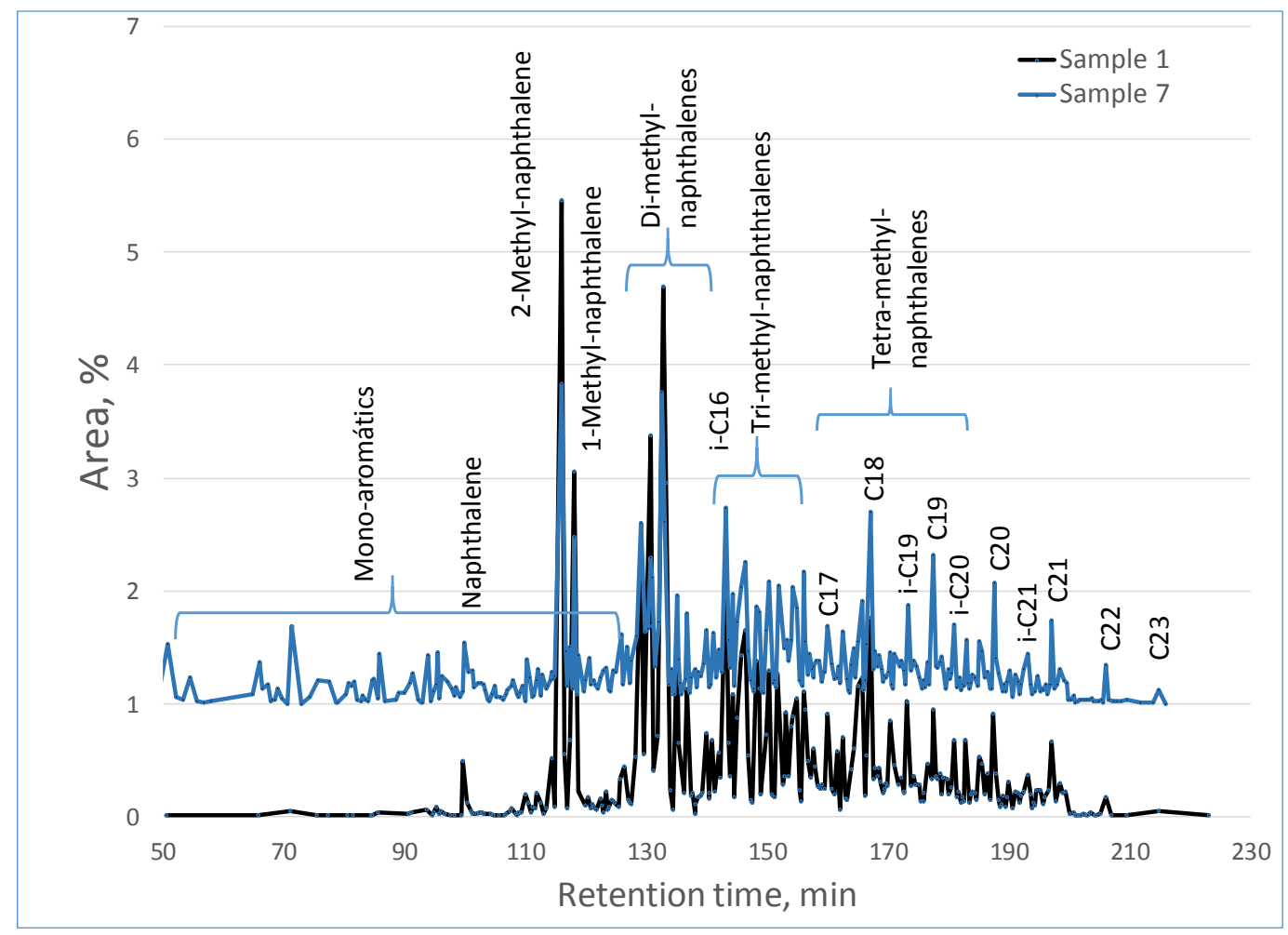

Figure4. Comparison of GC-MS chromatograms of LCO samples 1 and 7. 
Table 4 shows the characterization of the LCO samples according the lump separation depicted before. The presence of methyl-naphthalene (MN), di-methyl-naphthalene (DMN), tri-methyl-naphthalene (TMN) and tetra-methyl-naphthalene (TTMN) derivatives in the LCO samples were from 4.3 to 10.0, 12.1 to $28.5,13.8$ to 20.3 and 10.1 to 14.8 wt.\%, respectively. It is quite clear that, DMN and TMN derivatives were predominant in almost all studied samples, being the percentages of the average ratios 11.6, 31.4, 32.5, and 23.5.

Table4. GC-MS characterization by lumps of LCO samples 1 to 8

\begin{tabular}{|c|c|c|c|c|c|c|c|c|c|}
\hline LCO sample & 1 & 2 & 3 & 4 & 5 & 6 & 7 & 8 & Averaged \\
\hline & & & & & & & & & \\
\hline n-Alkanes, wt\% & 6.23 & 6.70 & 8.01 & 8.75 & 9.55 & 8.53 & 9.74 & 8.96 & 8.31 \\
\hline I-Alkanes, wt\% & 6.09 & 10.24 & 8.94 & 12.31 & 13.32 & 14.30 & 15.38 & 17.69 & 12.28 \\
\hline Benzene der. , wt\% & 9.48 & 24.54 & 12.85 & 20.47 & 16.89 & 28.00 & 21.08 & 13.04 & 18.29 \\
\hline Naphthalene, wt\% & 0.48 & 0.32 & 0.45 & 0.79 & 0.42 & 1.14 & 0.54 & 0.20 & 0.54 \\
\hline MN, wt\% & 8.26 & 9.99 & 6.47 & 6.74 & 4.39 & 5.11 & 4.33 & 4.86 & 6.27 \\
\hline DMN, wt\% & 28.46 & 14.90 & 19.06 & 16.30 & 18.24 & 13.74 & 12.15 & 14.94 & 17.22 \\
\hline TMN, wt\% & 20.31 & 13.79 & 16.41 & 17.28 & 16.74 & 16.95 & 18.06 & 19.94 & 17.44 \\
\hline TTMN, wt\% & 13.70 & 10.91 & 13.40 & 11.37 & 13.54 & 10.14 & 13.33 & 14.80 & 12.65 \\
\hline $\begin{array}{c}\text { Phenanthrene der. , } \\
\text { wt\% }\end{array}$ & 7.00 & 8.60 & 14.41 & 6.00 & 6.90 & 2.10 & 5.40 & 5.56 & 7.00 \\
\hline
\end{tabular}

It is noteworthy to remember that heavily alkylated naphthalenes, phenanthrene derivatives and aliphatic hydrocarbons are not suitable as feedstock for BTX production, and the presence of the tetramethylated aromatics are going to face difficulties during HYD for any upgrading purpose due to the steric hindrance exerted by these groups. Furthermore, it has been reported [16, 26] that as the number of methyl moieties attached to aromatic rings in naphthalene derivatives increases so does the difficulty for their hydrogenation to tetralin derivatives. Therefore, presence of large amounts of highly branched naphthalenes could affect the yield towards BTX fraction from a given LCO sample.

For the BTX production a term was defined as most suitable compounds for BTX production or MSCB, by summing up benzene, mono-, di- and tri-methylnaphthalene derivatives. In Figure 5 the LCO samples were ordered from the most to the least suitable.

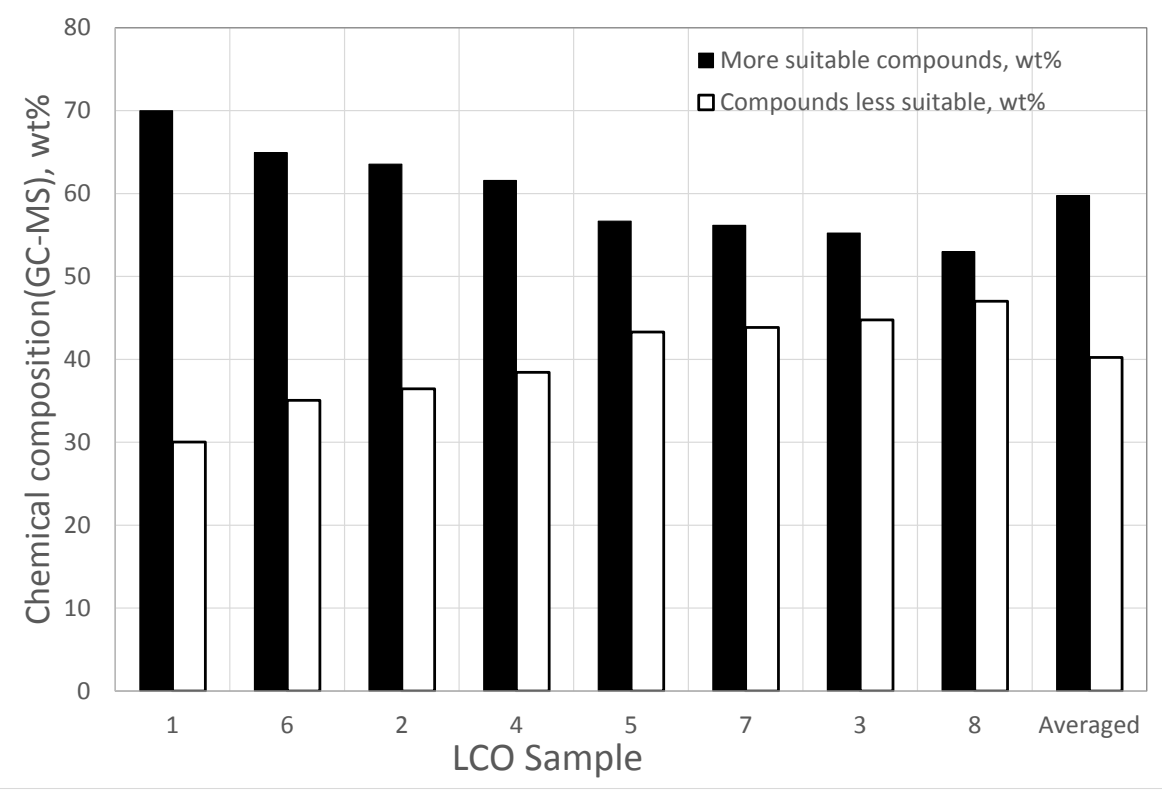

Figure5. Chemical composition of various LCO samples by the GC-MS method, from the most to the least suitable hydrocarbon type distribution for BTX production.

\subsection{Characterization of the Fractionated LCO Sample 6 by ASTM Methods.}

The results of some ASTM standards of the fractionated LCO sample 6 is shown on Table 5. Sulfur compounds presented the usual bimodal distribution where benzothiophenes appeared before $300{ }^{\circ} \mathrm{C}$ 
boiling point whereas dibenzothiophenes were identified after that temperature, as already disclosed in previous publications [1]. The nitrogen compounds increased as the boiling point of the fraction [1]. Carbazole type compounds are expected to be the main nitrogen compounds present [1].

Table5. Characterization of the $20^{\circ} \mathrm{C}$-boiling point fractions of LCO sample 6 according to used ASTM methods

\begin{tabular}{|c|c|c|c|c|c|c|c|c|c|c|}
\hline $\begin{array}{c}\text { Boiling point interval } \\
\left({ }^{\circ} \mathrm{C}\right)\end{array}$ & & $\begin{array}{c}175- \\
195\end{array}$ & $\begin{array}{c}195- \\
215\end{array}$ & $\begin{array}{c}215- \\
235\end{array}$ & $\begin{array}{c}235- \\
255\end{array}$ & $\begin{array}{c}255- \\
275\end{array}$ & $\begin{array}{c}275- \\
295\end{array}$ & $\begin{array}{c}295- \\
315\end{array}$ & $\begin{array}{c}315- \\
335\end{array}$ & $\begin{array}{c}>33 \\
5\end{array}$ \\
\hline $\begin{array}{c}\text { Distillated amount } \\
(\text { wt.\%) }\end{array}$ & $\begin{array}{c}\text { AST } \\
\mathrm{M}\end{array}$ & 1.82 & 1.87 & 8.53 & 15.98 & 19.88 & 19.98 & 11.87 & 10.54 & 9.52 \\
\hline Sulfur (wt\%) & $\begin{array}{c}\mathrm{D} 429 \\
4\end{array}$ & 0.90 & 1.42 & 2.95 & 4.41 & 4.39 & 3.20 & 2.58 & 3.45 & 3.82 \\
\hline Nitrogen (mg/kg) & $\begin{array}{c}\text { D462 } \\
9\end{array}$ & 138 & 179 & 139 & 189 & 351 & 343 & 199 & 522 & 145 \\
\hline $\begin{array}{c}\text { Chemical composition } \\
\text { (wt.\%) }\end{array}$ & $\begin{array}{c}\mathrm{D} 518 \\
3\end{array}$ & & & & & & & & & \\
\hline Mono-aromatics & & 63.9 & 60.7 & 48.9 & 17.8 & 8.9 & 6.2 & 4.8 & 4.2 & 4.4 \\
\hline Di-aromatics & & 15.3 & 22.3 & 35.8 & 69.1 & 78.2 & 76.8 & 60.4 & 36.8 & 19.9 \\
\hline Tri-aromatics & & 0.1 & 0.2 & 0.3 & 1.5 & 2.1 & 4.6 & 18.7 & 40.1 & 50.5 \\
\hline Total aromatics & & 79.3 & 83.2 & 85.0 & 88.4 & 89.2 & 87.6 & 83.9 & 81.1 & 74.8 \\
\hline Aliphatic & & 20.7 & 16.8 & 15.0 & 11.6 & 10.8 & 12.4 & 16.1 & 18.9 & 25.2 \\
\hline
\end{tabular}

The chemical composition obtained by using the ASTM D5186 followed the tendency reported previously [1,2]. As it was already discussed, both aliphatic and tri-aromatic hydrocarbons are not desirable when intending to use LCO as feedstock for BTX petrochemicals production $[24,27]$ although aliphatic hydrocarbons would be suitable for diesel [28]. Aliphatic compounds appeared all along the boiling point intervals from 10.8 to $25.2 \mathrm{wt} \%$. Clearly, higher heavy aliphatic concentration was registered at the upper end of the distillation curve and mostly of them were long n-alkane hydrocarbons. Tri-aromatics showed up in the $295-315{ }^{\circ} \mathrm{C}$ boiling point interval their amount increasing in heavier fractions. Evidently, final boiling point temperature should be lower than $295^{\circ} \mathrm{C}$ to eliminate that type of compounds in each LCO sample.

\subsection{Chemical Characterization of the Fractionated LCO Sample 6 by the GC-MS Method.}

The chemical characterization of $20^{\circ} \mathrm{C}$-boiling point fractions from LCO sample 6 according to the detailed GC-MS method previously described, is shown in Table 6 Phenanthrene (tri-aromatic) derivatives appeared in very low concentration in the $275-295{ }^{\circ} \mathrm{C}$ fraction notably increasing their amount in the subsequent heavier cuts. TTMN which did not show good reactivity towards hydrogenation aiming to tetralin formation $[16,26]$, were the main components exactly in the $295-315^{\circ} \mathrm{C}$ fraction, and it is convenient to avoid them.

Table6. Characterization of the $20^{\circ} \mathrm{C}$-boiling point fractions of LCO sample 6 according to the detailed GC-MS technique.

\begin{tabular}{|c|c|c|c|c|c|c|c|c|c|}
\hline $\begin{array}{c}\text { Boiling point interval } \\
\left({ }^{\circ} \mathrm{C}\right)\end{array}$ & $\begin{array}{c}175- \\
195\end{array}$ & $\begin{array}{c}195- \\
215\end{array}$ & $\begin{array}{c}215- \\
235\end{array}$ & $\begin{array}{c}235- \\
255\end{array}$ & $\begin{array}{c}255- \\
275\end{array}$ & $\begin{array}{c}275- \\
295\end{array}$ & $\begin{array}{c}295- \\
315\end{array}$ & $\begin{array}{c}315- \\
335\end{array}$ & $>335$ \\
\hline Distillation (wt.\%) & 1.82 & 1.87 & 8.53 & 15.98 & 19.88 & 19.98 & 11.87 & 10.54 & 9.52 \\
\hline n-Alkanes & 8.60 & 6.17 & 6.82 & 4.52 & 8.55 & 6.07 & 5.50 & 9.55 & 8 \\
\hline iso-Alkanes & 12.31 & 11.03 & 9.07 & 6.22 & 9.21 & 8.43 & 10.72 & 7.63 & 9.43 \\
\hline Benzene der. & 62.21 & 65.50 & 40.52 & 6.54 & 0.00 & 0.00 & 0.04 & 0.00 & 0.00 \\
\hline Naphthalene & 6.61 & 6.93 & 2.42 & 0.07 & 0.00 & 0.00 & 0.00 & 0.00 & 0.00 \\
\hline MN & 5.83 & 6.04 & 31.04 & 7.50 & 43.76 & 0.00 & 0.00 & 0.00 & 0.00 \\
\hline DMN & 3.63 & 4.10 & 10.05 & 73.76 & 37.96 & 8.27 & 0.00 & 0.00 & 0.00 \\
\hline TMN & 0.59 & 0.18 & 0.06 & 1.33 & 0.34 & 57.30 & 16.36 & 1.16 & 0.00 \\
\hline TTMN & & & & & & & & & 13.1 \\
& 0.05 & 0.06 & 0.04 & 0.06 & 0.18 & 19.33 & 58.50 & 37.87 & 5 \\
\hline & & & & & & & & & 60.5 \\
Phenanthrene der. & 0.16 & 0.00 & 0.00 & 0.00 & 0.00 & 0.60 & 8.88 & 43.79 & 3 \\
\hline
\end{tabular}

\subsection{Practical Relations to Apply for Selecting a Suitable LCO Feedstock for Upgrading.}

A better LCO for upgradeability purposes to BTX must possess a low value of FBP, to avoid highly methylated naphthalene and phenanthrenes derivatives as is shown in Figure 6. The lowest the value of 
the $90 \mathrm{vol} \%$ distillation boiling point was, the higher the more suitable hydrocarbons presence was. It is convenient that the LCO presented a high API value (Figure 7). A rapid suitability analysis may be carried out graphically after summing the mono- and di-aromatic compounds values obtained from the ASTM D5186 test versus the most suitable compounds for BTX (MSCB) and calculate according to Figure 8 .

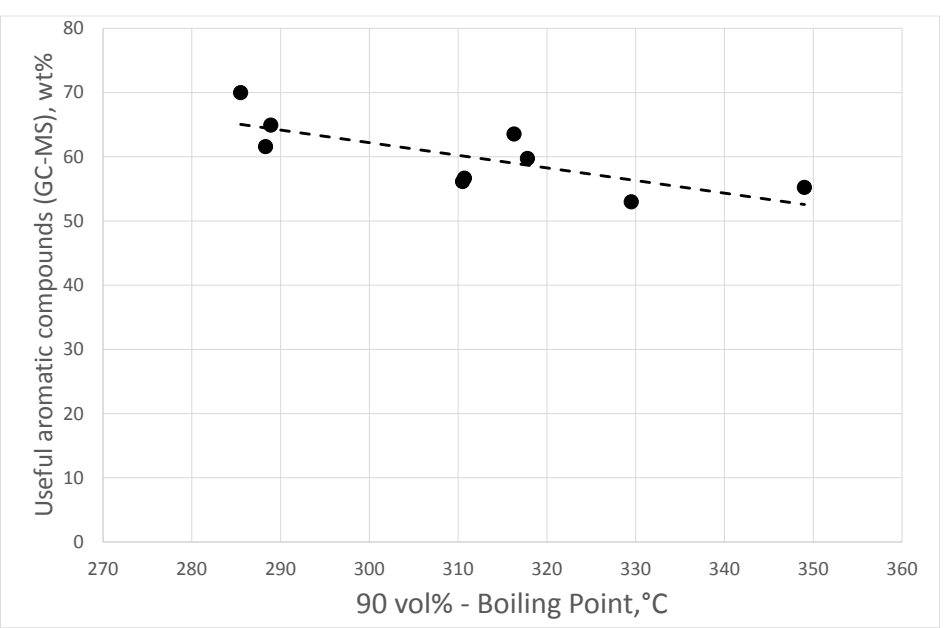

Figure6. Effect of the 90 vol\% distillation boiling point on the amount of the more suitable compounds for BTX production.

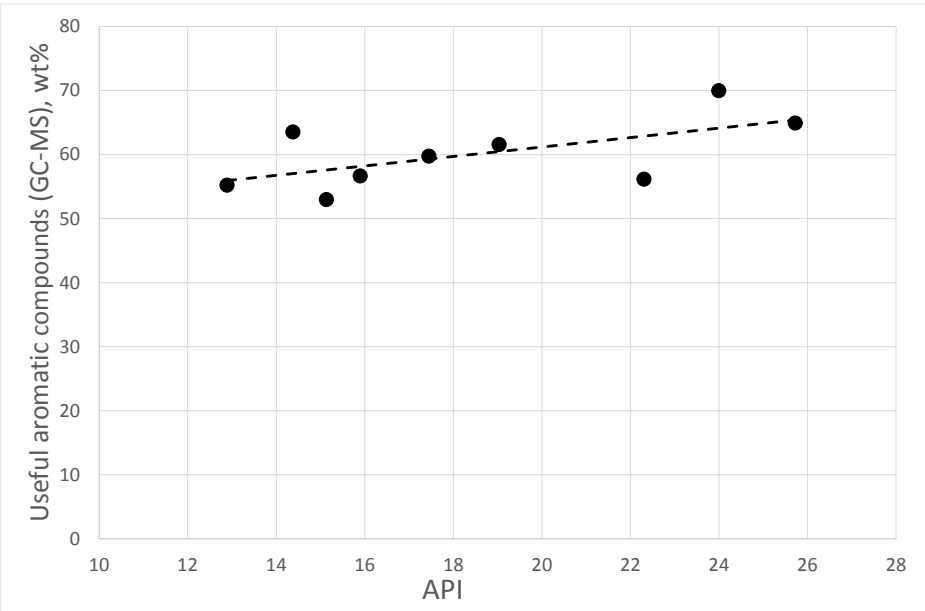

Figure7. Effect of the API on the amount of the more suitable compounds for BTX production

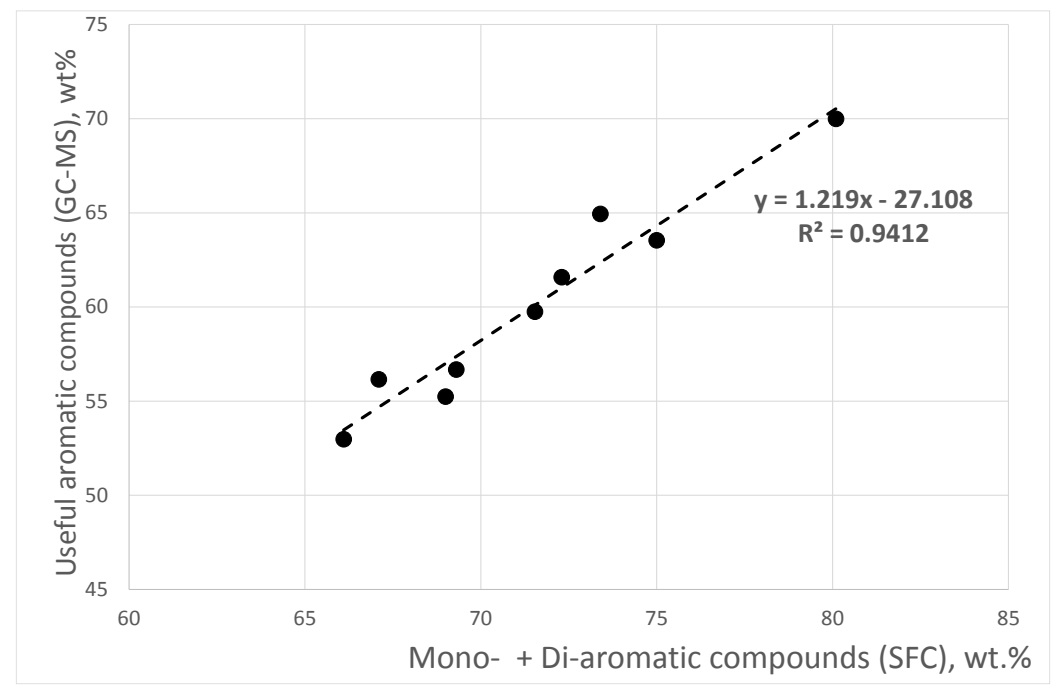

Figure8. Effect of the mono- + di-aromatic content on the amount of the more suitable compounds for BTX production 


\section{CONCLUSION}

A detailed chemical characterization of samples of LCO was presented. The method could be useful for decision-making regarding the suitability of certain distillate as feedstock for valuable petrochemicals (like benzene, toluene and xylene) production or gasoline. Detailed characterization allowed not just the usual separation as mono-, di- and tri-aromatic compounds, obtained by the ASTM D5186 method (supercritical fluid chromatography with flame ionization detection) but also provided information regarding the complexity of the naphthalene derivatives (mono-, di-, tri- o tetra-methyl-naphthalenes) which could have different reactivities during the hydrogenation-hydrocracking processes required when aiming to valuable petrochemicals or diesel production.

By using the provided data, the amount of the more suitable compounds for upgrading to BTX (MSCB) production was defined by summing up benzene, mono-, di- and tri-methylnaphthalene derivatives. This value presented an inverse relation with 90 vol\% boiling point and a direct relation with API. An equation relating the amount of mono- and di-aromatic compounds obtained by ASTM D55186 with the most suitable compounds for BTX (MSCB) value, is also provided.

\section{ACKNOWLEDGEMENT}

The authors are grateful for the financial support provided by Instituto Mexicano del Petróleo (IMP) through the research project D.61065.

\section{REFERENCES}

[1] Laredo G.C., Leyva S., Álvarez R., Mares M.T., Castillo J., Cano J.L. Nitrogen compounds characterization in atmospheric gas oil and light cycle oil from a blend of Mexican crudes. Fuel 81(10) 1341 (2002);

[2] Laredo G.C., Figueroa Y., Cano J.L., Mares M.T., Castillo J. Chemical composition of LCO obtained from Mexican crudes. Rev. Soc. Quím. Mex., 46(2), 115 (2002).

[3] Norma Oficial Mexicana de Emergencia NOM-EM-005-CRE-2015, Especificaciones de calidad de los petrolíferos. Diario Oficial de la Federación. 30/10/2015.

[4] https://www.epa.gov/diesel-fuel-standards/diesel-fuel-standards-rulemakings.

[5] Choi K.-H., Sano Y., Korai Y., Mochida I. An approach of deep desulfurization of light cycle oil. Appl. Catal. B. 53 (4), 275 (2004).

[6] Laredo G.C., Saint-Martin R., Martinez M.C., Castillo J., Cano J.L. High quality diesel by hydrotreating of atmospheric gas oil/light cycle oil blends. Fuel;83(10), 1381 (2004).

[7] Turaga U.T., Song C. MCM-41 support Co-Mo catalyst for deep hydrodesulfurization of light cycle oil. Catal. Today; 6 (1-4), 129 (2003).

[8] Yao S., Zheng Y., Ding L., Ng S., Yang H. Co-promotion of fluorine and boron on $\mathrm{NiMo} / \mathrm{Al}_{2} \mathrm{O}_{3}$ for hydrotreating light cycle oil. Catal. Sci. Technol. 2(9),1925 (2012).

[9] Azizi N., Ali S.A., Alhooshani K., Kim T., Lee Y., Park J-I., Miyawaki J., Yoon S-H., Mochida I. Hydrotreating of light cycle oil over NiMo and CoMo catalysts with different supports. Fuel Process. Technol. 109, 172 (2013).

[10] Yun G-N., Lee Y-K. Dispersion effects on $\mathrm{Ni}_{2} \mathrm{P}$ catalysts on hydrotreating of light cycle oil. Appl. Catal. B. 150-151 (May), 647 (2014).

[11] http://www.mustangeng.com/NewsandIndustryEvents/Publications/Publications/MUSTANGPTQ.pdf.

[12] Lee C.K., McGovern S. J., Zagorsk J. A. Refiners have many options to convert high-aromatic streams into ULSD. Oil \& Gas J. (05/15/2006).

[13] Bisht D., Petri J. Considerations regarding light cycle oil upgrading with hydroprocessing technologies. Ind. Chem. Eng. 56 (4), 321 (2014).

[14] Laredo G.C.; Perez Romo P., Escobar J., Garcia-Gutierrez J.L. Vega-Merino P. Light Cycle Oil Upgrading to Benzene, Toluene and Xylenes by Hydrocracking: Studies Using Model Mixtures. Ind. Eng. Chem. Res. 56 (39), 10939 (2017).

[15] https://www.astm.org/.

[16] Choi Y., Lee J., Shin J., Lee S., Kim D., Lee J.K. Selective hydroconversion of naphthalenes into light aromatics. Appl. Catal. 492 (Feb),140 (2015);

[17] Alonso D.E., Klitzke C. Blinkey J. Light and Middle Petroleum Distillate Characterization Using TwoDimensional Gas Chromatography-High-Resolution Time-of-Flight Mass Spectrometry and Enhanced Software Processing. Spectrometry. 14 (1), 21 (2016). 
[18] Vendeuvre C., Ruiz-Guerrero R., Bertoncini F., Duval L., Thiébaut D., Hennion M-Cl. Characterization of middle-distillates by comprehensive two-dimensional gas chromatography (GC x GC): A powerful alternative for performing various standard analysis of middle-distillates. J. Chromatogr. A,; 10861-2), 21 (2005).

[19] Ruiz-Guerrero R., Vendeuvre C., Thiébaut D., Bertoncini F., Espinat D. Comparison of comprehensive two-dimensional gas chromatography coupled with sulfur chemiluminescence detector to standard methods for speciation of sulfur-containing compounds in middle distillates. J. Chromatogr. Sci. 44(9), 566 (2006).

[20] Adam F., Thiébaut D., Bertoncini F., Mourtiade M., Hennion M-Cl., Supercritical fluid chromatography hyphenated with twin comprehensive two-dimensional gas chromatography for ultimate analysis of middle distillates. J Chromatogr. A, 1217 (8), 1386 (2010).

[21] Jennerwein M.K., Eschner M., Gröger Th., Wilharm Th., Zimmermann R. Complete group-type quantification of petroleum middle distillates based on comprehensive two-dimensional gas chromatography time-of-flight mass spectrometry (GCxGC-TOFMS) and visual basic scripting. Energy Fuels. 28 (9), 5670 (2014),

[22] Alvarez-Majmutov A., Gieleciak R., Chen J. Deriving the Molecular Composition of Vacuum Distillates by Integrating Statistical Modeling and Detailed Hydrocarbon Characterization. Energy Fuels 29(12). 7931 (2015).

[23] EPA. 1998. "Method 8270D (SW-846): Semivolatile Organic Compounds by Gas Chromatography/ Mass Spectrometry (GC/MS), Revision 4.

[24] Sahu R., Song B.J., Jeon Y-P., Lee C.W. A review of recent advances in catalytic hydrocracking of heavy residues. J. Ind. Eng. Chem. 27(July), 12 (2015).

[25] Palos R., Gutiérrez A., Arandes J.M., Bilbao J. Upgrading of High-Density Polyethylene and Light Cycle Oil Mixtures to Fuels via Hydroprocessing. Catal. Today 305 (May), 212 (2018).

[26] Kim Y.S., Yun G.N., Lee Y.K. Novel NiP/zeolite catalyst for hydrocracking of naphthalene to BTX. Chem. Commun. 45(Feb), 133 (2014);

[27] Zhang D., Zhao J., Zhang Y., Lu X. Catalytic hydrogenation of phenanthrene over $\mathrm{NiMo} / \mathrm{Al}_{2} \mathrm{O}_{3}$ catalysts as hydrogen storage intermediate. Int. J. Hydrogen Energ. 41 (27), 11675 (2016);

[28] Stanislaus A., Marafi A., Rana MS. Recent advances in the science and technology of ultra low sulfur diesel (ULSD) production. Catal. Today 153 (1-2), 1 (2010).

Citation: Georgina C. Laredo, et.al, "Detailed Characterization of Light Cycle Oil for BTX Production Purposes", International Journal of Forestry and Horticulture, 6(3), pp. 1-12. DOI: https:// doi.org/10.20431/2454-7980.0603001

Copyright: (C) 2020 Authors, this is an open-access article distributed under the terms of the Creative Commons Attribution License, which permits unrestricted use, distribution, and reproduction in any medium, provided the original author and source are credited. 